\title{
Identification of a Novel Locus Rmo2 Conditioning Resistance in Barley to Host-Specific Subgroups of Magnaporthe oryzae
}

\author{
Nguyen Thi Thanh Nga, Yoshihiro Inoue, Izumi Chuma, Gang-Su Hyon, Kazuma Okada, \\ Trinh Thi Phuong Vy, Motoaki Kusaba, and Yukio Tosa
}

\begin{abstract}
First, second, third, fourth, fifth, sixth, and eighth authors: Laboratory of Plant Pathology, Graduate School of Agricultural Science, Kobe University, Nada, Kobe 657-8501, Japan; seventh author: Faculty of Agriculture, Saga University, Honjo, Saga 804-8502, Japan. Current address of N. T. T. Nga: Agricultural Genetics Institute, Pham Van Dong Road, Tu Liem, Hanoi, Vietnam.

Current address of K. Okada: National Institute of Fruit Tree Science, National Agriculture and Food Research Organization (NARO),

Shimokuriyagawa, Morioka, Iwate 020-0123, Japan.
\end{abstract}

Accepted for publication 19 March 2012.

\begin{abstract}
Nga, N. T. T., Inoue, Y., Chuma, I., Hyon, G.-S., Okada, K., Vy, T. T. P., Kusaba, M., and Tosa, Y. 2012. Identification of a novel locus Rmo2 conditioning resistance in barley to host-specific subgroups of Magnaporthe oryzae. Phytopathology 102:674-682.

Barley cultivars show various patterns of resistance against isolates of Magnaporthe oryzae and M. grisea. Genetic mechanisms of the resistance of five representative barley cultivars were examined using a highly susceptible barley cultivar, 'Nigrate', as a common parent of genetic crosses. The resistance of the five cultivars against Setaria, Oryza,

pathogenicity suggested that each cultivar carries an allele at the Rmo2 locus that recognizes a different range of avirulence genes. One allele, Rmo2.a, corresponded to PWT1, which conditioned the avirulence of Setaria and Oryza isolates on wheat, in a gene-for-gene manner. The other alleles, Rmo2.b, Rmo2.c, and Rmo2.d, corresponded to more than one avirulence gene. On the other hand, the resistance of those cultivars to another species, M. grisea, was conditioned by another locus, designated as Rmo3. These results suggest that Rmo2 is effective against a broad range of blast isolates but is specific to M. oryzae. Molecular mapping revealed that $R m o 2$ is located on the $7 \mathrm{H}$ chromosome.
\end{abstract} Eleusine, and Triticum isolates of M. oryzae was all attributed to a single locus, designated as Rmo2. Nevertheless, the Rmo2 locus in each cultivar was effective against a different range of isolates. Genetic analyses of
Additional keywords: Hordeum vulgare.
Blast diseases of gramineous plants are caused by several species belonging to the genera Pyricularia (in anamorph) or Magnaporthe (in teleomorph) (10). Magnaporthe oryzae (4) is the most common species among them, and is found on various crops (e.g., rice, foxtail millet, finger millet, and wheat). However, isolates from each crop are almost exclusively pathogenic on their original host genus $(13,19)$, indicating that $M$. oryzae is composed of host genus-specific subgroups. Members of each subgroup have been called Oryza isolates, Setaria isolates, Eleusine isolates, Triticum isolates, and so on, using the host genus names. $M$. grisea is another member of the causal agents of blast diseases but is found only on Digitaria spp., including crabgrass (13); in other words, $M$. grisea consists of only one host-genus specific subgroup, Digitaria isolates.

Tosa and his coworkers $(19,20)$ performed genetic analyses of the subgroup-genus specificity using wheat as a model crop. Murakami et al. (16) found that the avirulence of a Setaria isolate (GFSI1-7-2) on wheat was conditioned by two genes, PWT1 and $P W T 2$. These genes were also involved in the avirulence of an Oryza isolate (PO12-7301-2) on wheat (20). Similarly, Takabayashi et al. (17) found that the avirulence of an Avena isolate (Br58) on wheat was conditioned by two genes, PWT3 and PWT4. Interestingly, common wheat 'Chinese Spring' did not recognize PWT4. By using this cultivar as a susceptible parent, they successfully identified a resistance gene corresponding to PWT4 and desig-

Corresponding author: Y. Tosa; E-mail address: tosayuki@kobe-u.ac.jp

* The $\boldsymbol{e}$-Xtra logo stands for "electronic extra" and indicates that the online version contains two supplemental figures.

http://dx.doi.org/10.1094/PHYTO-09-11-0256

(C) 2012 The American Phytopathological Society nated it as Rwt4. This was direct evidence that gene-for-gene interactions underlay the subgroup-genus specificity. We also tried to identify Rwt1, a putative resistance gene corresponding to PWT1, in common wheat, but failed in the identification because all hexaploid wheat lines tested recognized PWT1 (3).

Barley is another member of the family Triticeae that shares syntenic 7 chromosomes with wheat. Genetic analyses of blast resistance in barley have been performed in some laboratories. Yaegashi (22) reported that a half of his test cultivars were resistant to an isolate from barley while the others were susceptible. By using this specificity, he identified a blast resistance gene in barley and designated it as $P H R-1$. Inukai et al. (11) identified a resistance gene against a rice isolate in barley, and designated it as Rmol. In our preliminary screening, we found that the interaction between barley and $M$. oryzae included various types, from nonhost-like immune responses through host-like compatible responses. These findings suggested that the barley population had a lot of polymorphisms in terms of resistance or susceptibility to $M$. oryza and $M$. grisea subgroups. We hypothesized that such a high polymorphism might make it possible to identify resistance genes involved in host species specificity. The key material for such an analysis is an exceptional cultivar that is highly susceptible to any subgroup of $M$. oryzae and $M$. grisea. We found that barley 'Nigrate' had such an exceptional characteristic. Using this cultivar, we successfully identified a core locus conditioning the resistance of barley to various subgroups of $M$. oryzae.

\section{MATERIALS AND METHODS}

Plant and fungal materials. The plant materials used were six barley (Hordeum vulgare L.) cultivars and a common wheat 
(Triticum aestivum L.) cultivar, 'Norin 4' (N4) (Table 1). The barley and wheat cultivars were provided by Dr. U. Hiura, an emeritus professor at Okayama University, and Dr. K. Tsunewaki, an emeritus professor at Kyoto University, respectively.

Fungal isolates used were $M$. oryzae GFSI1-7-2 (Si-1J) isolated from foxtail millet (Setaria italica), PO12-7301-2 (O-23IN) isolated from rice (Oryza sativa), MZ5-1-6 (Ec-3J) isolated from finger millet (Eleusine coracana), $\mathrm{Br} 48$ (T-4B) isolated from common wheat (T. aestivum), and M. grisea Dig41 (Dsa-1J) isolated from crabgrass (Digitaria sanguinalis) (Table 1). The species of these isolates were identified by Hirata et al. (10) using genealogical concordance phylogenetic species recognition (18). In addition to these five isolates, $M$. oryzae $\mathrm{Br} 116.5$ (T-7B), isolated from common wheat, was used as a mating partner of an MAT1-1 culture. For segregation analyses of pathogenicity, the $\mathrm{F}_{1}$ cultures derived from Si-1J $\times$ T-4B (16) and O-23IN $\times$ T-4B (20) were employed. These isolates or cultures have been maintained on barley seed media in the Laboratory of Plant Pathology, Kobe University, as described previously (10). They were transferred to a potato dextrose agar slant just before use and grown at room temperature. For the experiments, 1-week-old to 3-month-old cultures were used.

Genetic crosses of fungal cultures. Fungal cultures were crossed on oatmeal agar medium (20 g of oatmeal, $10 \mathrm{~g}$ of agar, and $2.5 \mathrm{~g}$ of sucrose in $500 \mathrm{ml}$ of water) as described by Murakami et al. (16). In a cross between Ec-3J and T-4B, all ascospores were isolated from each ascus, and sister progenies were identified by fingerprinting with MGR583 $(9,12)$. A set of tetrads was established by choosing one culture from each sister progenies arbitrarily.

Bioassay. Barley and wheat seedlings were grown at $22^{\circ} \mathrm{C}$ for 7 days and inoculated with a conidial suspension ( 1 to $2 \times$ $10^{5}$ spores $/ \mathrm{ml}$ ) as described previously (16). After incubation in a dark, humid box at $22^{\circ} \mathrm{C}$ for 24 to $42 \mathrm{~h}$, they were returned to a growth chamber controlled at $22^{\circ} \mathrm{C}$ and incubated further. Five days after inoculation, infection types were determined based on the color (B, brown; $\mathrm{G}$, green) and the size of lesions (0, no visible evidence of infection; 1 , pinpoint spots; 2 , small lesions $<1.5 \mathrm{~mm}$ in diameter; 3 , scattered lesions with an intermediate to large size; 4, large, typical lesions; and 5, complete blighting of leaf blades). For example, infection type 1B represents brown lesions with size 1. Each infection assay was repeated three to five times.

To compare segregation patterns of resistance to different isolates, $F_{2}$ seedlings were sequentially inoculated with two isolates in various combinations with an interval of $24 \mathrm{~h}$. The first isolate was sprayed on primary leaves of the $\mathrm{F}_{2}$ seedlings, whose bottom half was covered with aluminum foil. After $24 \mathrm{~h}$ of incubation in a dark, humid box, the second isolate was sprayed on the same leaves, whose upper half was covered with aluminum foil. After incubation in the dark, humid box for additional $24 \mathrm{~h}$, they were transferred to a growth chamber with a $12-\mathrm{h}$ photoperiod. Disease intensity was evaluated 4 days after the second inoculation ( 5 days after the first inoculation).
Molecular mapping. Twenty seeds were retrieved from each of $91 \mathrm{~F}_{3}$ lines derived from a cross between resistant and susceptible cultivars, sown in vermiculite in a seedling case, and grown at $22^{\circ} \mathrm{C}$ in a controlled-environment room with a 12 -h photoperiod of fluorescent lighting for 7 days. Genomic DNA was extracted from 20 leaves following the procedure of Appels and Moran (1), with the modification by Koebner et al. (15), and used as a sample equivalent to the genomic DNA of the parental $F_{2}$ plant.

Out of simple-sequence repeat (SSR) loci reported by Varshney et al. (21), 11, 11, 11, 9, 13, 10, and 11 loci were chosen from the $1 \mathrm{H}, 2 \mathrm{H}, 3 \mathrm{H}, 4 \mathrm{H}, 5 \mathrm{H}, 6 \mathrm{H}$, and $7 \mathrm{H}$ chromosomes, respectively, so that they were distributed evenly on the chromosomes. They were amplified from genomic DNA of 10 "all resistant" and 10 "all susceptible" $F_{3}$ lines. Polymerase chain reaction (PCR) products were fractionated by electrophoresis through $6 \%$ denaturing polyacrylamide gels and stained using SILVER SEQUENCE DNA Staining Reagents (Promega Corp., Madison, WI).

After the target gene was found to be linked to an SSR marker located on $7 \mathrm{H}$, additional SSR loci were arbitrarily chosen from

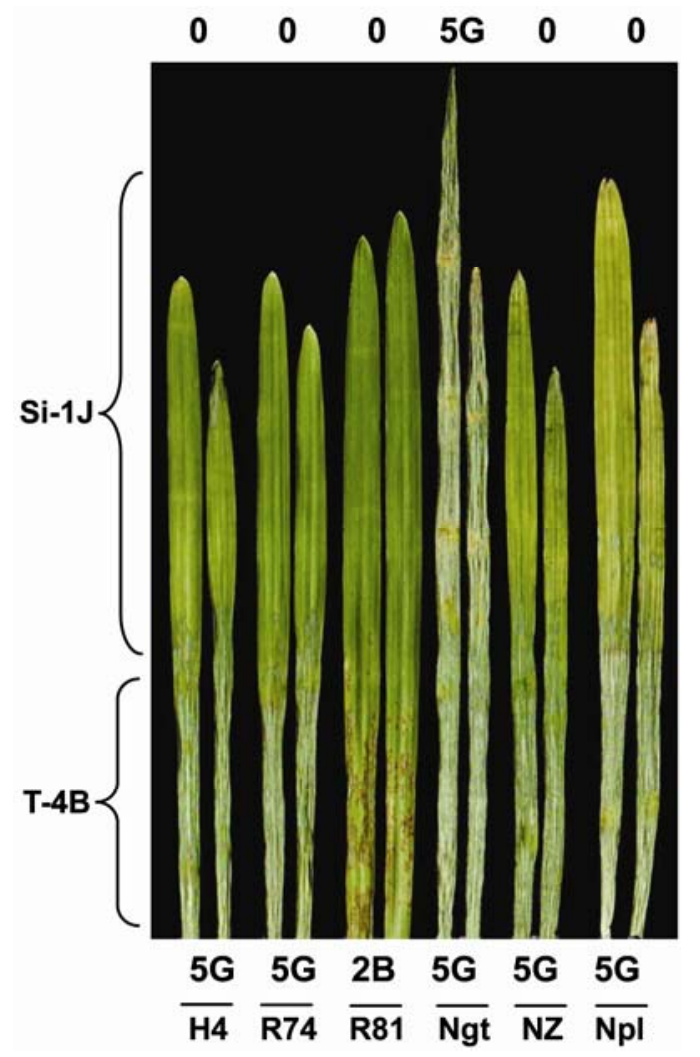

Fig. 1. Symptoms on primary leaves of parental cultivars that were sequentially inoculated with two isolates, 4 days after the second inoculation. The top half was first inoculated with $\mathrm{Si}-1 \mathrm{~J}$ and incubated for $24 \mathrm{~h}$; then, the bottom half was inoculated with T-4B. Infection types with $\mathrm{Si}-1 \mathrm{~J}$ and $\mathrm{T}-4 \mathrm{~B}$ are shown at the top and bottom of the panel.

TABLE 1. Infection types of barley cultivars with Magnaporthe isolates

\begin{tabular}{|c|c|c|c|c|c|}
\hline \multirow[b]{2}{*}{ Cultivar (abbreviation) } & \multicolumn{5}{|c|}{ Infection type with ${ }^{\mathrm{a}}$} \\
\hline & GFSI1-7-2 (Si-1J) & PO12-7301-2 (O-23IN) & MZ5-1-6 (Ec-3J) & $\mathrm{Br} 48(\mathrm{~T}-4 \mathrm{~B})$ & Dig41 (Dsa-1J) \\
\hline H.E.S.4 (H4) & $0 *$ & $0 *$ & $5 \mathrm{G}$ & $5 \mathrm{G}$ & $5 \mathrm{G}$ \\
\hline Nakaizumi-zairai (NZ) & $0 *$ & $0 *$ & $5 \mathrm{G}$ & $5 \mathrm{G}$ & $5 \mathrm{G}$ \\
\hline Nepal (Npl) & $0 *$ & $0 *$ & $5 \mathrm{G}$ & $5 \mathrm{G}$ & $2 \mathrm{~B}^{*}$ \\
\hline Russian 74 (R74) & $0 *$ & $0^{*}$ & $2 \mathrm{~B} *$ & $4-5 G$ & $4 \mathrm{G}$ \\
\hline Russian 81 (R81) & $0^{*}$ & $3 \mathrm{BG}^{*}$ & $2 \mathrm{~B} *$ & $2 \mathrm{~B} *$ & $2 \mathrm{~B} *$ \\
\hline Nigrate (Ngt) & $5 \mathrm{G}$ & $4 \mathrm{G}$ & $5 \mathrm{G}$ & $5 \mathrm{G}$ & $5 \mathrm{G}$ \\
\hline
\end{tabular}

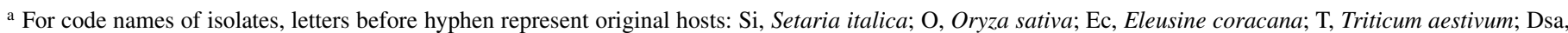

Digitaria sanguinalis. An asterisk (*) indicates an incompatible interaction. 
those on $7 \mathrm{H}(21)$, and amplified from genomic DNA of the $91 \mathrm{~F}_{3}$ lines. PCR products were fractionated as described above. Segregation data were analyzed using MAPMAKER Macintosh V2.0 with the $F_{2}$ intercross program. Thresholds of linkage for map construction were a minimum $\log$ of the likelihood ration of 4.0 and a maximum recombination fraction of 0.4 . The Kosambi mapping function was employed to compute map distances in centimorgans.

\section{RESULTS}

Infection types on barley cultivars caused by subgroups of $M$. oryzae and M. grisea. The six barley cultivars were inoculated with a Setaria isolate (Si-1J), an Oryza isolate (O-23IN), an Eleusine isolate (Ec-3J), a Triticum isolate (T-4B), and a Digitaria isolate (Dsa-1J). Infection types were classified into two categories: 0-3BG (resistant or avirulent) and 3G-5G (susceptible or virulent). 3BG was classified into the resistant group because green blast lesions in this type were surrounded by brown tissues derived from hypersensitive reaction (HR) (data not shown). 'H.E.S.4' (H4) and 'Nakaizumi-zairai' (NZ) showed the same pattern of reactions; resistant to $\mathrm{Si}-1 \mathrm{~J}$ and $\mathrm{O}-23 \mathrm{IN}$ but susceptible to the others (Table 1). 'Nepal' (Npl) and 'Russian 74' (R74) were resistant to Dsa-1J and Ec-3J, respectively, in addition to $\mathrm{Si}-1 \mathrm{~J}$ and O-23IN. 'Russian 81' (R81) was resistant to all isolates, although its resistance to O-23IN was very weak (3BG). On the other hand, Nigrate (Ngt) was susceptible to all isolates tested (Table 1).

Identification of resistance genes. Against $\mathrm{Si}-1 \mathrm{~J}$, all cultivars except Ngt showed strong resistance with no visible symptoms (infection type 0) (Table 1). When $\mathrm{F}_{2}$ populations derived from crosses between the five resistant cultivars and Ngt were inoculated with $\mathrm{Si}-1 \mathrm{~J}$, resistant and susceptible seedlings segregated in a 3:1 ratio (Table 2; Supplemental Figure 1), suggesting that the resistance of each cultivar to $\mathrm{Si}-1 \mathrm{~J}$ is controlled by a single major gene. Crosses between the resistant cultivars yielded no susceptible seedlings (Table 2), suggesting that the resistance genes in these cultivars are located at the same locus.

Against O-23IN, four cultivars (H4, NZ, Npl, and R74) were resistant while Ngt was susceptible (Table 1 ). When $F_{2}$ populations derived from crosses between the four cultivars and $\mathrm{Ngt}$ were inoculated with O-23IN, resistant and susceptible seedlings segregated in a 3:1 ratio (Table 2), suggesting that the resistance of each cultivar to O-23IN is controlled by a single major gene. Crosses between the resistant cultivars yielded no susceptible seedlings (Table 2), suggesting that the resistance genes in these cultivars are located at the same locus. The resistance of R81 to $\mathrm{O}-23 \mathrm{IN}$ was weak (infection type $3 \mathrm{BG}$ ) (Table 1). When an $\mathrm{F}_{2}$ population from $\mathrm{R} 81 \times \mathrm{Ngt}$ was inoculated with O-23IN, the distribution of infection types was not discontinuous (data not shown). Therefore, this interaction (between R81 and O-23IN) was excluded from the further analysis.

Against Ec-3J, two cultivars (R74 and R81) were resistant while the others were susceptible (Table 1 ). When $\mathrm{F}_{2}$ populations derived from $\mathrm{R} 74 \times \mathrm{Ngt}$ and $\mathrm{R} 81 \times \mathrm{Ngt}$ were inoculated with Ec$3 \mathrm{~J}$, resistant and susceptible seedlings segregated in a 3:1 ratio (Table 2). However, a cross between R74 and R81 yielded no susceptible seedlings (Table 2). These results suggest that the resistance of R74 and R81 to Ec-3J is controlled by a single gene located at the same locus.

TABLE 2. Distribution of infection types with Magnaporthe isolates in $\mathrm{F}_{2}$ populations derived from crosses between barley cultivars

\begin{tabular}{|c|c|c|c|c|c|c|c|c|c|c|c|c|c|}
\hline \multirow[b]{3}{*}{ Isolate, cross } & \multicolumn{11}{|c|}{ Number of $\mathrm{F}_{2}$ seedlings } & \multirow[b]{3}{*}{$\chi^{2}(3: 1)$} & \multirow[b]{3}{*}{$P$} \\
\hline & \multicolumn{8}{|c|}{ Infection type } & \multirow[b]{2}{*}{ Total } & \multirow[b]{2}{*}{ Resistant $^{\mathrm{a}}$} & \multirow[b]{2}{*}{ Susceptible ${ }^{b}$} & & \\
\hline & 0 & $1 \mathrm{~B}$ & 2B & 2BG & $3 \mathrm{~B} / 3 \mathrm{BG}$ & $3 \mathrm{G}$ & $4 \mathrm{G}$ & $5 \mathrm{G}$ & & & & & \\
\hline \multicolumn{14}{|l|}{$\mathrm{Si}-1 \mathrm{~J}$} \\
\hline $\mathrm{H} 4 \times \mathrm{Ngt}$ & 127 & 21 & 32 & 0 & 0 & 0 & 23 & 40 & 243 & 180 & 63 & 0.11 & 0.73 \\
\hline $\mathrm{NZ} \times \mathrm{Ngt}$ & 96 & 32 & 52 & 0 & 0 & 0 & 26 & 29 & 235 & 180 & 55 & 0.31 & 0.57 \\
\hline $\mathrm{Npl} \times \mathrm{Ngt}$ & 44 & 13 & 31 & 2 & 0 & 0 & 9 & 19 & 118 & 90 & 28 & 0.10 & 0.75 \\
\hline $\mathrm{R} 74 \times \mathrm{Ngt}$ & 123 & 2 & 3 & 0 & 0 & 0 & 3 & 34 & 165 & 128 & 37 & 0.58 & 0.44 \\
\hline $\mathrm{R} 81 \times \mathrm{Ngt}$ & 177 & 7 & 0 & 0 & 0 & 0 & 6 & 46 & 236 & 184 & 52 & 1.11 & 0.29 \\
\hline $\mathrm{H} 4 \times \mathrm{NZ}$ & 296 & 0 & 0 & 0 & 0 & 0 & 0 & 0 & 296 & 296 & 0 & $\ldots$ & $\ldots$ \\
\hline $\mathrm{H} 4 \times \mathrm{Npl}$ & 258 & 0 & 0 & 0 & 0 & 0 & 0 & 0 & 258 & 258 & 0 & $\ldots$ & $\ldots$ \\
\hline $\mathrm{H} 4 \times \mathrm{R} 74$ & 311 & 0 & 0 & 0 & 0 & 0 & 0 & 0 & 311 & 311 & 0 & $\ldots$ & $\ldots$ \\
\hline $\mathrm{H} 4 \times \mathrm{R} 81$ & 282 & 0 & 0 & 0 & 0 & 0 & 0 & 0 & 282 & 282 & 0 & $\ldots$ & $\ldots$ \\
\hline $\mathrm{R} 74 \times \mathrm{Npl}$ & 287 & 0 & 0 & 0 & 0 & 0 & 0 & 0 & 287 & 287 & 0 & $\ldots$ & $\ldots$ \\
\hline $\mathrm{R} 74 \times \mathrm{R} 81$ & 300 & 0 & 0 & 0 & 0 & 0 & 0 & 0 & 300 & 300 & 0 & $\ldots$ & $\ldots$ \\
\hline $\mathrm{R} 81$ × NZ & 306 & 0 & 0 & 0 & 0 & 0 & 0 & 0 & 306 & 306 & 0 & $\ldots$ & $\ldots$ \\
\hline $\mathrm{R} 81 \times \mathrm{Npl}$ & 235 & 0 & 0 & 0 & 0 & 0 & 0 & 0 & 235 & 235 & 0 & $\ldots$ & $\ldots$ \\
\hline \multicolumn{14}{|l|}{$\mathrm{O}-23 \mathrm{IN}$} \\
\hline $\mathrm{H} 4 \times \mathrm{Ngt}$ & 183 & 0 & 0 & 0 & 0 & 0 & 3 & 57 & 243 & 183 & 60 & 0.01 & 0.91 \\
\hline $\mathrm{NZ} \times \mathrm{Ngt}$ & 185 & 0 & 2 & 0 & 0 & 0 & 3 & 59 & 249 & 187 & 62 & 0.00 & 0.97 \\
\hline $\mathrm{Npl} \times \mathrm{Ngt}$ & 163 & 0 & 0 & 0 & 0 & 0 & 1 & 49 & 213 & 163 & 50 & 0.26 & 0.60 \\
\hline $\mathrm{R} 74 \times \mathrm{Ngt}$ & 181 & 0 & 1 & 0 & 0 & 0 & 1 & 64 & 247 & 182 & 65 & 0.22 & 0.63 \\
\hline $\mathrm{H} 4 \times \mathrm{NZ}$ & 286 & 0 & 0 & 0 & 0 & 0 & 0 & 0 & 286 & 286 & 0 & $\ldots$ & $\ldots$ \\
\hline $\mathrm{H} 4 \times \mathrm{Npl}$ & 262 & 0 & 0 & 0 & 0 & 0 & 0 & 0 & 262 & 262 & 0 & $\ldots$ & $\ldots$ \\
\hline $\mathrm{H} 4 \times \mathrm{R} 74$ & 296 & 0 & 0 & 0 & 0 & 0 & 0 & 0 & 296 & 296 & 0 & $\ldots$ & $\ldots$ \\
\hline $\mathrm{R} 74 \times \mathrm{Npl}$ & 274 & 0 & 0 & 0 & 0 & 0 & 0 & 0 & 274 & 274 & 0 & $\ldots$ & $\ldots$ \\
\hline \multicolumn{14}{|l|}{ Ec-3J } \\
\hline $\mathrm{R} 74 \times \mathrm{Ngt}$ & 14 & 14 & 31 & 65 & 0 & 0 & 0 & 47 & 171 & 124 & 47 & 0.56 & 0.45 \\
\hline $\mathrm{R} 81 \times \mathrm{Ngt}$ & 99 & 82 & 78 & 0 & 0 & 0 & 0 & 85 & 344 & 259 & 85 & 0.01 & 0.90 \\
\hline $\mathrm{R} 74 \times \mathrm{R} 81$ & 135 & 20 & 58 & 0 & 0 & 0 & 0 & 0 & 213 & 213 & 0 & $\ldots$ & $\ldots$ \\
\hline \multicolumn{14}{|l|}{$\mathrm{T}-4 \mathrm{~B}$} \\
\hline $\mathrm{R} 81 \times \mathrm{Ngt}$ & 0 & 1 & 47 & 94 & 0 & 0 & 1 & 48 & 191 & 142 & 49 & 0.04 & 0.84 \\
\hline \multicolumn{14}{|l|}{ Dsa-1J } \\
\hline $\mathrm{Npl} \times \mathrm{Ngt}$ & 26 & 13 & 16 & 25 & 0 & 0 & 5 & 19 & 104 & 80 & 24 & 0.20 & 0.65 \\
\hline $\mathrm{R} 81 \times \mathrm{Ngt}$ & 9 & 30 & 99 & 24 & 0 & 0 & 0 & 61 & 223 & 162 & 61 & 0.66 & 0.42 \\
\hline $\mathrm{R} 81 \times \mathrm{Npl}$ & 133 & 29 & 40 & 0 & 0 & 0 & 0 & 0 & 202 & 202 & 0 & $\ldots$ & $\ldots$ \\
\hline
\end{tabular}

${ }^{\text {a }}$ Infection type 0 to $3 \mathrm{BG}$.

b Infection type $3 \mathrm{G}$ to $5 \mathrm{G}$. 
Against T-4B, R81 was resistant while the others were susceptible (Table 1). When an $\mathrm{F}_{2}$ population derived from $\mathrm{R} 81 \times \mathrm{Ngt}$ was inoculated with T-4B, resistant and susceptible seedling segregated in a 3:1 ratio (Table 2), suggesting that the resistance of $\mathrm{R} 81$ to $\mathrm{T}-4 \mathrm{~B}$ is controlled by a single gene.

Against Dsa-1J, two cultivars ( $\mathrm{Npl}$ and $\mathrm{R} 81$ ) were resistant while the others were susceptible (Table 1). Crosses between $\mathrm{Npl}$ or R81 and Ngt produced resistant and susceptible $\mathrm{F}_{2}$ seedling in a 3:1 ratio but a cross between Npl and R81 yielded no susceptible seedlings (Table 2). These results suggest that the resistance of Npl and R81 to Dsa-1J is controlled by a single gene located at the same locus.

Allelic relationships of the resistance genes. The segregation analyses mentioned above revealed that the resistance of the barley cultivars to each isolate was controlled by the same gene. To determine whether the resistance of each cultivar to different isolates was controlled by the same gene, we performed "double inoculation" in which seedlings were sequentially inoculated with two different isolates with a 24-h interval. When the six parental cultivars were first inoculated with SI-1J (virulent on a cultivar and avirulent on the others) and then with $\mathrm{T}-4 \mathrm{~B}$ (avirulent on a cultivar and virulent on the others), they showed the same infection types as those inoculated with $\mathrm{Si}-1 \mathrm{~J}$ alone and $\mathrm{T}-4 \mathrm{~B}$ alone, respectively (Fig. 1; Table 1). This result indicates that infection types with the second inoculum are not affected by the first inoculation; or, in other words, that the effect of induced resistance can be neglected in this system.

H4, NZ, Npl, and R74 were resistant to both Si-1J and O-23IN. $\mathrm{F}_{2}$ seedlings from $\mathrm{H} 4 \times \mathrm{Ngt}, \mathrm{NZ} \times \mathrm{Ngt}, \mathrm{Npl} \times \mathrm{Ngt}$, and $\mathrm{R} 74 \times \mathrm{Ngt}$ were inoculated first with Si-1J and then with O-23IN. In all $\mathrm{F}_{2}$ populations, seedlings resistant to $\mathrm{Si}-1 \mathrm{~J}$ were also resistant to $\mathrm{O}$ 23IN while those susceptible to $\mathrm{Si}-1 \mathrm{~J}$ were also susceptible to O23IN (Table 3). This result suggests that the resistance genes against $\mathrm{Si}-1 \mathrm{~J}$ and $\mathrm{O}-23 \mathrm{IN}$ identified in these cultivars are located at the same locus.

R74 was resistant not only to $\mathrm{Si}-1 \mathrm{~J}$ and O-23IN but also to Ec3J (Table 1). The segregation patterns against these three isolates were perfectly concordant in $\mathrm{F}_{2}$ seedlings from $\mathrm{R} 74 \times \mathrm{Ngt}$ (Table 3 ), suggesting that the resistance genes against the three isolates are located at the same locus in R74.

R81 was resistant not only to $\mathrm{Si}-1 \mathrm{~J}$ and $\mathrm{Ec}-3 \mathrm{~J}$ but also to T-4B (Table 1). The segregation patterns against these three isolates were perfectly concordant in $\mathrm{F}_{2}$ seedlings from $\mathrm{R} 81 \times \mathrm{Ngt}$ (Table 3 ), suggesting that the resistance genes against the three isolates are located at the same locus in R81. To confirm this conclusion directly, $\mathrm{F}_{3}$ populations derived from $\mathrm{R} 81 \times \mathrm{Ngt}$ were inoculated with Si-1J, Ec-3J, and T-4B. With all three isolates, all resistant, segregating, and susceptible populations segregated in a 1:2:1 ratio (Table 4 ). The segregation patterns with the three isolates were perfectly concordant (Table 4). These results support the conclusion drawn from the double inoculation of $\mathrm{F}_{2}$ seedlings.

Taken together, the resistance of all cultivars to all $M$. oryzae isolates tested in the present study was attributed to a single locus. This locus was designated as Rmo2, following the designation proposed by Inukai et al. (11). On the other hand, the resistance (of Npl and R81) to M. grisea (Dsa-1J) was controlled by another locus. When $\mathrm{F}_{2}$ seedlings from $\mathrm{Npl} \times \mathrm{Ngt}$ and $\mathrm{R} 81 \times \mathrm{Ngt}$ were inoculated first with $M$. oryzae (O-23IN, Si-1J, Ec-3J, or T-4B) and then with $M$. grisea (Dsa-1J), recombinants were observed (Table 3). However, the segregation of RpRq (resistant to both), $\mathrm{RpSq}$ (resistant to the former and susceptible to the latter), SpRq (susceptible to the former and resistant to the latter), and $\mathrm{SpSq}$ (susceptible to both) was significantly deviated from a ratio which was expected from independent inheritance (Table 3). These results suggest that the resistance of Npl and R81 to Dsa-1J is controlled by a locus that is distinct from but linked to Rmo2. This locus (and gene) against M. grisea was designated as $R m o 3$.

Identification of avirulence genes. The results mentioned above suggest that the resistance of those cultivars against $M$. oryzae is conditioned by a single gene at the Rmo2 locus. Nevertheless, these cultivars are resistant to various ranges of $M$. oryzae subgroups. One possible explanation is that they carry different

TABLE 3. Segregation of reactions to two Magnaporthe isolates in $F_{2}$ populations derived from crosses between resistant and susceptible barley cultivars

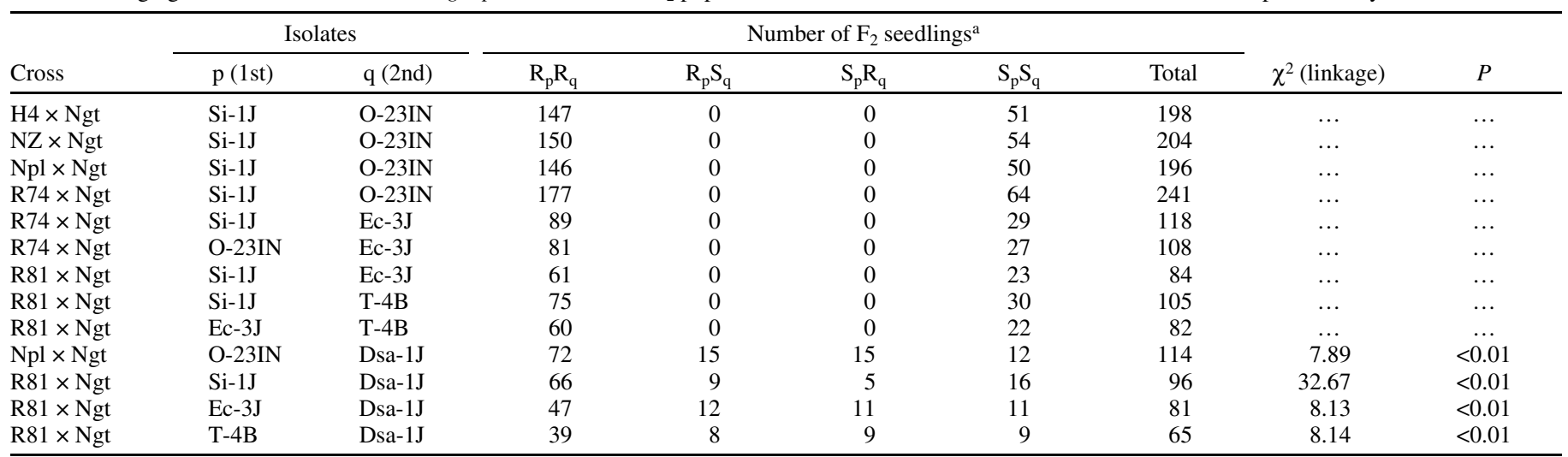

${ }^{a} \mathrm{R}=$ resistant (infection type 0 to $3 \mathrm{BG}$ ) and $\mathrm{S}=$ susceptible (infection type $3 \mathrm{G}$ to $5 \mathrm{G}$ ). For example, $\mathrm{R}_{\mathrm{p}} \mathrm{S}_{\mathrm{q}}$ represents seedlings which are resistant to $\mathrm{p}$ and susceptible to q.

TABLE 4. Segregation of reactions to Magnaporthe oryzae isolates in $\mathrm{F}_{3}$ populations derived from $\mathrm{R} 81 \times \mathrm{Ngt}$

\begin{tabular}{lcccccc}
\hline & \multicolumn{5}{c}{ Number of $\mathrm{F}_{3}$ populations $^{\mathrm{a}}$} & \multirow{2}{*}{$\chi^{2}(1: 2: 1)$} \\
\cline { 2 - 5 } Isolate & All resistant & Segregating & All susceptible & Total & 0.08 \\
Si-1J & 13 & 24 & 13 & 50 & 0.96 \\
Ec-3J & $13^{\mathrm{b}}$ & $24^{\mathrm{c}}$ & $13^{\mathrm{d}}$ & 50 & 0.08 & 0.96 \\
T-4B & $13^{\mathrm{b}}$ & $24^{\mathrm{c}}$ & $13^{\mathrm{d}}$ & 50 & 0.08 & 0.96 \\
\hline
\end{tabular}

a The same 50 populations were used for all isolates. Twenty seeds were retrieved from each population for infection assay with each isolate.

${ }^{b}$ The 13 populations that were all resistant to Si-1J.

${ }^{c}$ The 24 populations that were segregating to Si-1J.

$\mathrm{d}$ The 13 populations that were all susceptible to $\mathrm{Si}-1 \mathrm{~J}$. 
alleles at the Rmo2 locus that correspond to different (ranges of) avirulence genes. To examine whether this is the case, segregation analyses were performed using hybrid populations derived from crosses between the $M$. oryzae isolates.

The avirulence of $\mathrm{Si}-1 \mathrm{~J}$ on the five barley cultivars $(\mathrm{H} 4, \mathrm{NZ}$, $\mathrm{Npl}$, R74, and R81) was analyzed using the $\mathrm{F}_{1}$ population between $\mathrm{Si}-1 \mathrm{~J}$ (GFSI1-7-2) and T-4B (Br48) produced by Murakami et al. (16). This $F_{1}$ population was composed of 10 tetrads (40 cultures). Of the 40 cultures, 5 mutants that lost the basic capacity of penetration were excluded, and the remaining 35 were sprayed on wheat N4, which had been used for the identification of $P W T 1$ (associated with the brown lesion color and HR) and PWT2 (associated with the lesion number and papilla formation). Murakami et al. (16) recognized four phenotypes on N4 inoculated with the $\mathrm{F}_{1}$ population: $\mathrm{B}-(\approx 0$ to $2 \mathrm{~B}), \mathrm{B}+(\approx 4$ to $5 \mathrm{~B})$, $\mathrm{G}-(\approx 3 \mathrm{G})$, and $\mathrm{G}+(\approx 4$ to $5 \mathrm{G})$. In the present study, $4 \mathrm{~B}$ or $5 \mathrm{~B}$ were not observed due to the lower temperature $\left(21\right.$ to $\left.22^{\circ} \mathrm{C}\right)$ compared with $25^{\circ} \mathrm{C}$ used by Murakami et al. (16). The lower temperature made it easier to recognize the segregation of PWT1. In the present condition, $P W T 1$ and $p w t 1$ carriers showed infection types 0 to $3 \mathrm{~B}$ and $3 \mathrm{G}$ to $5 \mathrm{G}$, respectively, on $\mathrm{N} 4$. When these two categories of infection types were assumed to be avirulent and virulent, their segregation fitted a 1:1 ratio, as expected (Table 5). The segregation of $P W T 2$ seemed to be reflected to the peak at
3G among the pwtl carriers (Table 5). However, the lesion number was affected by a fluctuation of concentration and viability of inocula. To simplify the analysis, we focused on the segregation of $P W T 1$ playing the primary role in the avirulence of Si-1J.

When $\mathrm{H} 4$ and $\mathrm{NZ}$ were inoculated with the $\mathrm{F}_{1}$ population derived from $\mathrm{Si}-1 \mathrm{~J} \times \mathrm{T}-4 \mathrm{~B}$, avirulent and virulent cultures also segregated in a 1:1 ratio (Table 5). The segregation patterns on these barley cultivars were perfectly concordant with that on N4 (Table 6), suggesting that $\mathrm{H} 4$ and NZ recognize $P W T 1$. When Npl and R74 were inoculated with the $\mathrm{F}_{1}$ population, avirulent and virulent cultures segregated in a 3:1 ratio (Table 5), suggesting that two genes are involved in the avirulence of Si-1J on each of these cultivars. If one of the two genes is PWT1 detected on N4, the combined segregation on N4 and Npl or R74 should fit a 2:0:1:1 ratio (Supplemental Figure 2). If none of the two genes is $P W T 1$, the combined segregation should fit a 3:1:3:1 ratio. When the segregation data on $\mathrm{N} 4$ and $\mathrm{Npl}$ or R74 were combined, there were no cultures that were avirulent on $\mathrm{N} 4$ and virulent on $\mathrm{Npl}$ or R74 (Table 6); in other words, the PWT1 carriers were all avirulent on $\mathrm{Npl}$ and R74. The segregation of ApAq (avirulent on both $\mathrm{N} 4$ and Npl/R74), VpAq (virulent on N4 and avirulent on $\mathrm{Npl} / \mathrm{R} 74$ ), and $\mathrm{VpVq}$ (virulent on both) fitted in a 2:1:1 ratio. These results suggest that one of the two genes detected on $\mathrm{Npl}$

TABLE 5. Segregation of virulence on wheat and barley cultivars in $\mathrm{F}_{1}$ populations derived from crosses between field isolates of Magnaporthe oryzae

\begin{tabular}{|c|c|c|c|c|c|c|c|c|c|c|c|}
\hline \multirow[b]{3}{*}{ Cross, cultivar } & \multicolumn{9}{|c|}{ Number of $F_{1}$ cultures } & & \\
\hline & \multicolumn{6}{|c|}{ Infection type } & \multirow[b]{2}{*}{ Avirulent $^{\mathrm{a}}$} & \multirow[b]{2}{*}{ Virulent $^{\mathrm{b}}$} & \multirow[b]{2}{*}{ Total } & \multicolumn{2}{|c|}{$\chi^{2}$ for $^{c}$} \\
\hline & $0 / 1 \mathrm{~B}$ & $2 \mathrm{~B} / 2 \mathrm{BG}$ & $3 \mathrm{~B} / 3 \mathrm{BG}$ & $3 \mathrm{G}$ & $4 \mathrm{G}$ & $5 \mathrm{G}$ & & & & $1: 1$ & $3: 1$ \\
\hline \multicolumn{12}{|l|}{$\mathrm{Si}-1 \mathrm{~J} \times \mathrm{T}-4 \mathrm{~B}$} \\
\hline $\mathrm{N} 4^{\mathrm{d}}$ & 10 & 9 & 1 & 8 & 2 & 5 & 20 & 15 & 35 & 0.71 & $5.95 *$ \\
\hline $\mathrm{H} 4$ & 7 & 12 & 1 & 1 & 5 & 9 & 20 & 15 & 35 & 0.71 & $5.95 *$ \\
\hline $\mathrm{NZ}$ & 9 & 9 & 2 & 2 & 3 & 10 & 20 & 15 & 35 & 0.71 & $5.95 *$ \\
\hline $\mathrm{Npl}$ & 10 & 11 & 4 & 0 & 5 & 5 & 25 & 10 & 35 & $6.42 *$ & 0.29 \\
\hline $\mathrm{R} 74$ & 13 & 13 & 1 & 2 & 2 & 4 & 27 & 8 & 35 & $10.31 * *$ & 0.09 \\
\hline $\mathrm{R} 81$ & 12 & 18 & 3 & 0 & 0 & 2 & 33 & 2 & 35 & $27.45^{* *}$ & $6.94 * *$ \\
\hline \multicolumn{12}{|l|}{$\mathrm{O}-23 \mathrm{IN} \times \mathrm{T}-4 \mathrm{~B}$} \\
\hline $\mathrm{H} 4$ & 2 & 11 & 5 & 3 & 4 & 11 & 18 & 18 & 36 & 0.00 & $12.00 * *$ \\
\hline $\mathrm{NZ}$ & 2 & 9 & 7 & 3 & 6 & 9 & 18 & 18 & 36 & 0.00 & $12.00 * *$ \\
\hline $\mathrm{Npl}$ & 12 & 4 & 7 & 3 & 4 & 6 & 23 & 13 & 36 & 2.78 & 2.37 \\
\hline $\mathrm{R} 74$ & 16 & 9 & 2 & 0 & 1 & 8 & 27 & 9 & 36 & $9.00 * *$ & 0.00 \\
\hline \multicolumn{12}{|l|}{$\mathrm{Ec}-3 \mathrm{~J} \times \mathrm{T}-4 \mathrm{~B}$} \\
\hline $\mathrm{R} 74$ & 2 & 17 & 0 & 0 & 5 & 16 & 19 & 21 & 40 & 0.10 & $16.14 * *$ \\
\hline R81 & 3 & 27 & 0 & 0 & 5 & 5 & 30 & 10 & 40 & $10.00 * *$ & 0.00 \\
\hline
\end{tabular}

a Infection type 0 to $3 \mathrm{BG}$.

b Infection type $3 \mathrm{G}$ to $5 \mathrm{G}$.

c Significant at the 5\% (*) and $1 \%(* *)$ levels.

d Wheat 'Norin 4' on which PWT1 was identified.

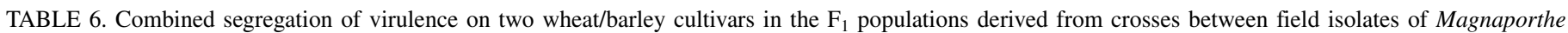
oryzae

\begin{tabular}{|c|c|c|c|c|c|c|c|c|}
\hline \multirow[b]{2}{*}{ Cross } & \multicolumn{2}{|c|}{ Cultivar } & \multicolumn{4}{|c|}{ Number of $F_{1}$ cultures $^{a}$} & \multicolumn{2}{|c|}{$\chi^{2}$ for $^{\mathrm{b}}$} \\
\hline & $\mathrm{p}$ & $\mathrm{q}$ & $\mathrm{A}_{\mathrm{p}} \mathrm{A}_{\mathrm{q}}$ & $\mathrm{A}_{\mathrm{p}} \mathrm{V}_{\mathrm{q}}$ & $\mathrm{V}_{\mathrm{p}} \mathrm{A}_{\mathrm{q}}$ & $\mathrm{V}_{\mathrm{p}} \mathrm{V}_{\mathrm{q}}$ & Total & $2:(0:) 1: 1$ \\
\hline \multirow[t]{6}{*}{$\mathrm{Si}-1 \mathrm{~J} \times \mathrm{T}-4 \mathrm{~B}$} & $\mathrm{~N} 4^{\mathrm{c}}$ & $\mathrm{H} 4$ & 20 & 0 & 0 & 15 & 35 & $\ldots$ \\
\hline & N4 & $\mathrm{NZ}$ & 20 & 0 & 0 & 15 & 35 & $\ldots$ \\
\hline & N4 & $\mathrm{Npl}$ & 20 & 0 & 5 & 10 & 35 & 2.14 \\
\hline & N4 & R74 & 20 & 0 & 7 & 8 & 35 & 0.77 \\
\hline & N4 & $\mathrm{R} 81$ & 20 & 0 & 13 & 2 & 35 & $7.63 *$ \\
\hline & $\mathrm{Npl}$ & R74 & 23 & 2 & 4 & 6 & 35 & $\ldots$ \\
\hline \multirow[t]{4}{*}{$\mathrm{O}-23 \mathrm{IN} \times \mathrm{T}-4 \mathrm{~B}$} & $\mathrm{H} 4$ & NZ & 18 & 0 & 0 & 18 & 36 & $\ldots$ \\
\hline & $\mathrm{H} 4$ & $\mathrm{Npl}$ & 18 & 0 & 5 & 13 & 36 & 3.56 \\
\hline & $\mathrm{H} 4$ & R74 & 17 & 1 & 10 & 8 & 36 & $\ldots$ \\
\hline & $\mathrm{Npl}$ & $\mathrm{R} 74$ & 22 & 1 & 5 & 8 & 36 & $\ldots$ \\
\hline $\mathrm{Ec}-3 \mathrm{~J} \times \mathrm{T}-4 \mathrm{~B}$ & R74 & R81 & 19 & 0 & 11 & 10 & 40 & 0.01 \\
\hline
\end{tabular}

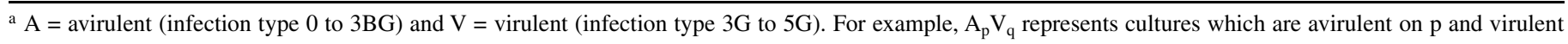
on q.

b An asterisk (*) indicates a value significant at the 5\% level.

c Wheat 'Norin 4' on which PWT1 was identified. 
and R74 is PWT1. When the segregation patterns of Npl and R74 were combined, both recombinants $(\mathrm{ApVq}$ and $\mathrm{VpAq})$ were observed (Table 6), indicating that different genes are involved in the avirulence on $\mathrm{Npl}$ and $\mathrm{R} 74$ in addition to the common gene, $P W T 1$. The genes specifically detected on $\mathrm{Npl}$ and $\mathrm{R} 74$ were tentatively designated as $A V R-X s$ and $A V R-Y s$, respectively ("s" indicates derived from a Setaria isolate). R81 was resistant to both parents of the $F_{1}$ population (Table 1 ). When R81 was inoculated with the $\mathrm{F}_{1}$ population, two virulent cultures were observed (Table 5), indicating that the avirulence of $\mathrm{Si}-1 \mathrm{~J}$ and $\mathrm{T}-4 \mathrm{~B}$ are conditioned by different genes. However, the segregation of avirulent and virulent cultures did not fit a 3:1 ratio (Table 5), suggesting that those genes are linked or that more than two genes are involved.

The avirulence of O-23IN on the four barley cultivars (H4, NZ, $\mathrm{Npl}$, and R74) was analyzed using the $\mathrm{F}_{1}$ population derived from the cross between O-23IN (PO12-7301-2) and T-4B (20). Of the 14 tetrads produced by Tosa et al. (20), 9 tetrads were chosen

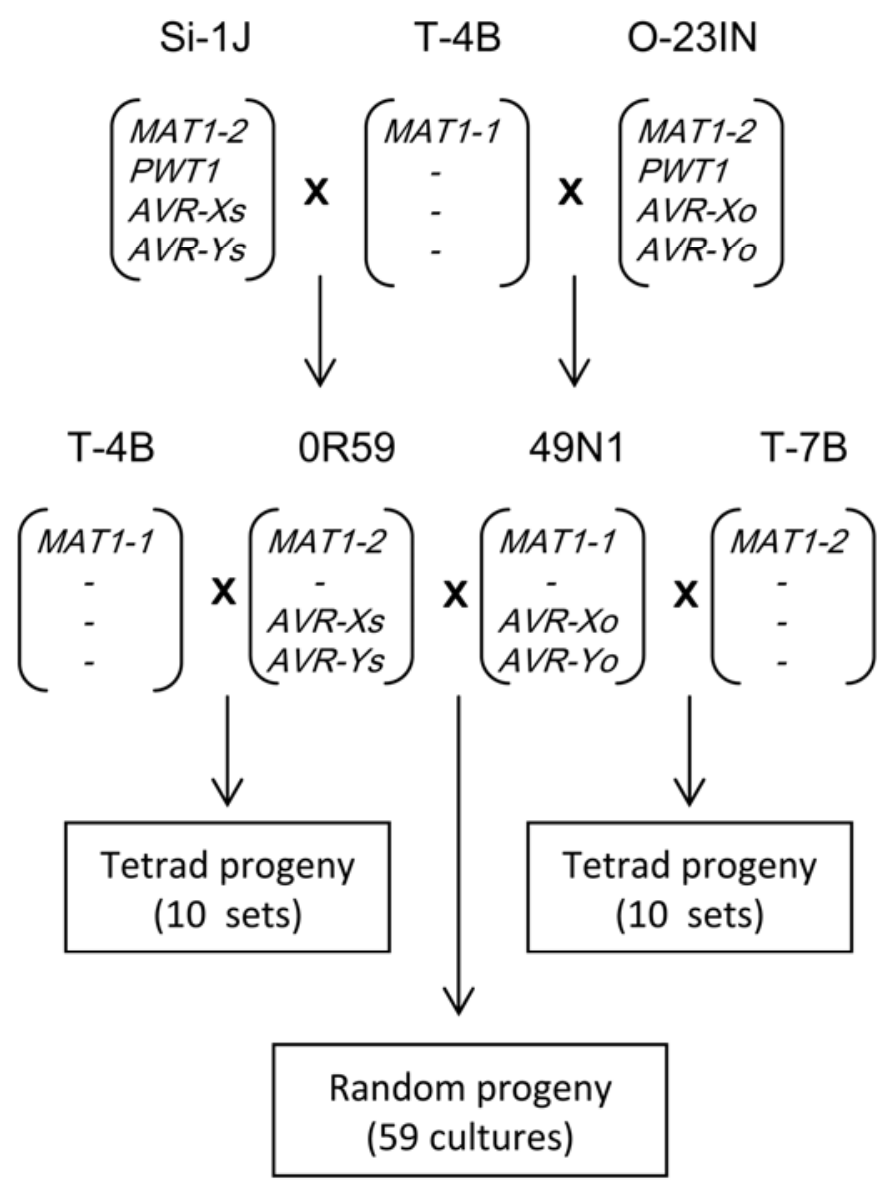

Fig. 2. Genetic crosses for checking allelic relationships among $A V R-X s$, $A V R-Y s, A V R-X o$, and AVR-Yo. which did not contain mutant cultures lacking the basic capacity of penetration. When $\mathrm{H} 4$ and NZ were inoculated with the 36 cultures $(=4 \times 9)$, avirulent and virulent cultures segregated in a 1:1 ratio (Table 5). The segregation patterns on these cultivars were perfectly concordant (Table 6). These results suggest that the avirulence of $\mathrm{O}-23 \mathrm{IN}$ on $\mathrm{H} 4$ and $\mathrm{NZ}$ is controlled by the same, single gene as in the case of the avirulence of $\mathrm{Si}-1 \mathrm{~J}$ on these cultivars. This gene was considered to be PWTI because O-23IN had been already reported to carry PWTl (20). On Npl, the segregation of avirulent and virulent cultures was not significantly different from 1:1 or 3:1 ratios (Table 5). However, the PWT1 carriers (cultures avirulent on $\mathrm{H} 4$ ) were all avirulent on $\mathrm{Npl}$ whereas the pwtl carriers (cultures virulent on H4) were composed of avirulent and virulent cultures on Npl (Table 6). These results suggest that, in addition to $P W T 1$, one gene is involved in the avirulence on $\mathrm{Npl}$. This gene was tentatively designated as $A V R-X o$ ("o" indicates derived from an Oryza isolate). On R74, avirulent and virulent cultures segregated in a 3:1 ratio (Table 5), suggesting that two genes are involved. One of the two genes should be PWT1 because R74 recognized PWT1 derived from Si$1 \mathrm{~J}$. When the segregation patterns on $\mathrm{H} 4$ and R74 were combined, the cultures avirulent on $\mathrm{H} 4$ were also avirulent on R74, with one exception (Table 6). On the other hand, the cultures virulent on H4 were avirulent or virulent on R74 in a 1:1 ratio (10:8). This gene was tentatively designated as AVR-Yo.

To analyze the avirulence of Ec-3J on R74 and R81, Ec-3J was crossed with T-4B, and 10 tetrads were isolated (see Materials and Methods). R74 was resistant to Ec-3J but susceptible to T-4B (Table 1). When R74 was inoculated with the $40 \mathrm{~F}_{1}$ cultures, avirulent and virulent cultures segregated in a 1:1 ratio (Table 5), suggesting that one gene is involved in the avirulence of Ec-3J on R74. This gene was designated as PBY1 (for "pathogenicity on barley"). On the other hand, R81 was resistant to both parental isolates (Table 1). When R81 was inoculated with the $40 \mathrm{~F}_{1}$ cultures, the segregation fitted a 3:1 ratio (Table 5), suggesting that this $F_{1}$ population contains two avirulence genes, one from Ec-3J and the other from T-4B. When the segregation patterns on R74 and R81 were combined, all of the cultures avirulent on R74 were also avirulent on R81 while the cultures virulent on R74 were split into two groups, (i.e., avirulent and virulent on R81) in a 1:1 ratio (Table 6). These results suggest that the avirulence gene from Ec-3J detected on R81 is PBY1. The other gene (from T-4B) detected on R81 was designated as $P B Y 2$.

Allelic relationships of the avirulence genes detected in Si1J and O-23IN. Si-1J carried $A V R-X s$ and $A V R-Y s$ in addition to $P W T 1$ while O-23IN carried $A V R-X o$ and $A V R-Y o$ in addition to $P W T 1$. $A V R-X s$ and $A V R-X o$ were specifically detected on $\mathrm{Npl}$ while $A V R-Y s$ and $A V R-Y o$ were specifically detected on R74. A simple hypothesis is that $A V R-X s$ and $A V R-X o$ are the same gene while $A V R-Y s$ and $A V R-Y o$ are the same gene. This hypothesis was tested as illustrated in Figure 2.

$0 \mathrm{R} 59$, an $\mathrm{F}_{1}$ culture derived from $\mathrm{Si}-1 \mathrm{~J} \times \mathrm{T}-4 \mathrm{~B}$, was virulent on $\mathrm{H} 4$ but avirulent on $\mathrm{Npl}$ and $\mathrm{R} 74$ and, therefore, was considered to carry $A V R-X s$ and $A V R-Y s$ but not $P W T 1$ (Fig. 2). This culture

TABLE 7. Segregation of virulence on barley cultivars in populations derived from crosses involving $A V R-X$ and $A V R-Y$ carriers

\begin{tabular}{|c|c|c|c|c|c|}
\hline \multirow[b]{2}{*}{ Cross } & \multirow[b]{2}{*}{ Cultivar } & \multicolumn{3}{|c|}{ Number of progeny cultures } & \multirow[b]{2}{*}{$\chi^{2}$ for $1: 1$} \\
\hline & & Avirulent ${ }^{\mathrm{a}}$ & Virulent $^{\mathrm{b}}$ & Total & \\
\hline \multirow{2}{*}{$0 \mathrm{R} 59 \times \mathrm{T}-4 \mathrm{~B}$} & $\mathrm{Npl}$ & 20 & 19 & 39 & $0.03^{c}$ \\
\hline & R74 & 20 & 19 & 39 & $0.03^{\mathrm{c}}$ \\
\hline $49 \mathrm{~N} 1 \times \mathrm{T}-7 \mathrm{~B}$ & R74 & 21 & 19 & 40 & $0.10^{\mathrm{c}}$ \\
\hline \multirow[t]{2}{*}{$0 \mathrm{R} 59 \times 49 \mathrm{~N} 1$} & $\mathrm{Npl}$ & 59 & 0 & 59 & $\ldots$ \\
\hline & R74 & 59 & 0 & 59 & $\ldots$ \\
\hline
\end{tabular}

${ }^{\text {a }}$ Infection type 0 to $3 \mathrm{BG}$.

${ }^{\mathrm{b}}$ Infection type $3 \mathrm{G}$ to $5 \mathrm{G}$.

${ }^{\mathrm{c}}$ Not significant at the 5\% level. 
was interfertile with T-4B because it carried the MAT1-2 allele at the mating type locus that was opposite to the MAT1-1 allele in T4B. 0R59 was backcrossed with T-4B, and 10 tetrads were obtained. Among a total of 40 cultures, 1 culture had lost the basic capacity of penetration. When $\mathrm{Npl}$ and R74 were inoculated with the remaining 39 cultures, avirulent and virulent cultures segregated in a 1:1 ratio on both cultivars, as expected (Table 7). When the segregation patterns on $\mathrm{Npl}$ and R74 were combined, recombinants (ApVq and $\mathrm{VpAq}$ ) were observed but much fewer than those expected from independent inheritance; the segregation of ApAq:ApVq:VpAq: $\mathrm{VpVq}$ was significantly deviated from a 1:1:1:1 ratio (Table 8 ). These results suggest that $A V R-X s$ and $A V R-Y s$ are linked.

The $\mathrm{F}_{1}$ population derived from $\mathrm{O}-23 \mathrm{IN} \times \mathrm{T}-4 \mathrm{~B}$ also contained several cultures that were virulent on $\mathrm{H} 4$ but avirulent on $\mathrm{Npl}$ and R74. They were considered to carry $A V R-X o$ and $A V R-Y o$ but not $P W T 1$. Out of these cultures, $49 \mathrm{~N} 1$ carrying the MAT1-1 mating type was chosen, and crossed with T-7B carrying the MAT1-2 mating type (Fig. 2). T-7B (Br116.5), a Triticum isolate collected in Brazil, was virulent on all of $\mathrm{H} 4, \mathrm{Npl}$, and $\mathrm{R} 74$ as $\mathrm{T}-4 \mathrm{~B}$, and was also considered to carry none of PWT1, AVR-Xo, and AVR-Yo. From this cross, 10 tetrads (in total, 40 cultures) were obtained. When Npl and R74 were inoculated with the 40 cultures, avirulent and virulent cultures segregated in a 1:1 ratio on both cultivars, as expected (Table 7). When the segregation patterns on $\mathrm{Npl}$ and R74 were combined, recombinants (ApVq and VpAq) were observed but, again, much fewer than those expected from independent inheritance (Table 8). These results suggest that $A V R$ $X o$ and $A V R$ - $Y o$ are linked.

Finally, 0R59 (MAT1-2) was crossed with 49N1 (MAT1-1). In this cross, one ascospore was arbitrarily chosen from ascospores in each ascus and isolated. The resulting hybrid population was composed of 59 random cultures derived from 59 asci (59 meiotic events) (Fig. 2). When Npl and R74 were inoculated with the 59 cultures, no virulent cultures were observed (Table 7). This result suggests that the hypothesis is correct: $A V R-X s$ and $A V R-X o$ are the same gene while $A V R-Y s$ and $A V R-Y o$ are the same gene. Here, we designate $A V R-X s / X o$ and $A V R-Y s / Y o$ as $P B Y 3$ and PBY4, respectively.

Molecular mapping of the Rmo2 locus. To map the Rmo2 locus, $91 \mathrm{~F}_{2}$ plants derived from the cross $\mathrm{NZ} \times \mathrm{Ngt}$ were grown in a field and selfed. From each of the resulting $91 \mathrm{~F}_{3}$ lines, a portion (20 seeds) was retrieved and used for inoculation with $\mathrm{O}$ 23IN. All resistant, segregating, and susceptible $\mathrm{F}_{3}$ lines were 23, 50 , and 18 , fitting a $1: 2: 1$ ratio $\left(\chi^{2}=1.44,0.1<P<0.5\right)$, as expected. Based on these $F_{3}$ reactions, genotypes of the $F_{2}$ plants at the Rmo2 locus were determined.
Another portion (20 seeds) was retrieved from each of the $91 \mathrm{~F}_{3}$ lines, grown for 7 days, and pooled for DNA extraction. Selected SSR loci (see Materials and Methods) were amplified from these DNA samples. Genotypes of the $\mathrm{F}_{2}$ plants at each SSR locus were determined based on banding patterns of the amplicons on polyacrylamide gel electrophoresis gels. When these molecular data were combined with the inoculation data, the Rmo2 locus was mapped on the chromosome 7H (Fig. 3).

\section{DISCUSSION}

Inukai et al. (11) identified a gene for resistance to an Oryza isolate (Ken54-20) of M. oryzae in a barley cultivar, and designated it as Rmol. Rmol was located on the $1 \mathrm{H}$ chromosome. $R m o 2$, a locus for resistance to $M$. oryzae identified in the present study, is apparently distinct from Rmol because Rmo2 is located on the 7H chromosome. Rmo3, a locus for resistance to $M$. grisea, should also be distinct from Rmol because $R m o 3$ is linked to Rmo2.

The resistance of the five barley cultivars to the four isolates of M. oryzae was all attributed to the Rmo2 locus. On the other hand, the resistance of those cultivars to another species, $M$. grisea, was conditioned by another locus, Rmo3. These results suggest that $R m o 2$ is effective against a broad range of blast isolates but is specific to $M$. oryzae. Interestingly, the $R m o 2$ genes in those cultivars were effective against different ranges of $M$. oryzae isolates (or subgroups). The segregation analyses of pathogenicity revealed that this is because the Rmo2 locus in each cultivar recognizes a different range of avirulence genes. Here, we assume that each cultivar carries an allele at the Rmo2 locus. Interactions of these alleles with the avirulence genes are summarized in Table 9. The allele in $\mathrm{H} 4$ and $\mathrm{NZ}$ corresponds to PWT1 alone, and is designated as Rmo2.a. The allele in Npl corresponds to PWT1 and $P B Y 3$, and is designated as Rmo2.b. The allele in R74 corresponds to $P W T 1, P B Y 4$, and $P B Y 1$, and is designated as Rmo2.c. The allele in R81 corresponds to at least $P B Y 1$ and $P B Y 2$, and is designated as Rmo2.d. With respect to the interaction between Rmo2.c and PWT1, some data were difficult to interpret: the $\mathrm{F}_{1}$ population derived from $\mathrm{O}-23 \times \mathrm{T}-4 \mathrm{~B}$ contained one exceptional culture that was avirulent on $\mathrm{H} 4$ and virulent on R74. Further research is necessary to test this unique culture.

Chuma et al. (3) showed that $P W T 1$ was recognized by $\mathrm{H} 4, \mathrm{NZ}$, and $\mathrm{Npl}$ using $63 \mathrm{BC}_{1} \mathrm{~F}_{1}$ cultures isolated randomly. The present study showed that the recognition was conditioned by Rmo2.a in $\mathrm{H} 4 / \mathrm{NZ}$ and Rmo2.b in Npl. It should be noted that Rmo2.a corresponded to $P W T 1$ in a gene-for-gene manner in barley- $M$. oryzae interactions. PWT1 was first identified as a gene con-

TABLE 8. Combined segregation of virulence on two barley cultivars in the populations derived from crosses involving AVR-X and AVR-Y carriers

\begin{tabular}{|c|c|c|c|c|c|c|c|c|}
\hline \multirow[b]{2}{*}{ Cross } & \multicolumn{2}{|c|}{ Cultivar } & \multicolumn{5}{|c|}{ Number of progeny cultures ${ }^{a}$} & \multirow[b]{2}{*}{$\chi^{2}$ for $1: 1: 1: 1^{\mathrm{b}}$} \\
\hline & $\mathrm{p}$ & $\mathrm{q}$ & $\mathrm{A}_{\mathrm{p}} \mathrm{A}_{\mathrm{q}}$ & $A_{p} V_{q}$ & $\mathrm{~V}_{\mathrm{p}} \mathrm{A}_{\mathrm{q}}$ & $\mathrm{V}_{\mathrm{p}} \mathrm{V}_{\mathrm{q}}$ & Total & \\
\hline $0 \mathrm{R} 59 \times \mathrm{T}-4 \mathrm{~B}$ & $\mathrm{Npl}$ & R74 & 18 & 2 & 2 & 17 & 39 & $24.69 * *$ \\
\hline $49 \mathrm{~N} 1 \times \mathrm{T}-7 \mathrm{~B}$ & $\mathrm{Npl}$ & R74 & 17 & 3 & 4 & 16 & 40 & $17.00 * *$ \\
\hline
\end{tabular}

${ }^{\mathrm{a}} \mathrm{A}=$ avirulent (infection type 0 to $3 \mathrm{BG}$ ) and $\mathrm{V}=$ virulent (infection type $3 \mathrm{G}$ to $5 \mathrm{G}$ ). For example, $\mathrm{A}_{\mathrm{p}} \mathrm{V}_{\mathrm{q}}$ represents cultures which are avirulent on $\mathrm{p}$ and virulent on q.

b Asterisks (**) indicate significant at the $1 \%$ level.

TABLE 9. Interactions between alleles at the Rmo2 locus in barley cultivars and avirulence genes in Magnaporthe oryzae

\begin{tabular}{|c|c|c|c|c|c|c|}
\hline \multirow[b]{2}{*}{ Allele } & \multirow[b]{2}{*}{ Carrier } & \multicolumn{5}{|c|}{ Interaction with genes ${ }^{\mathrm{a}}$} \\
\hline & & $P W T 1(\mathrm{Si}-1 \mathrm{~J}, \mathrm{O}-23 \mathrm{IN})$ & $P B Y 3(\mathrm{Si}-1 \mathrm{~J}, \mathrm{O}-23 \mathrm{IN})$ & PBY4 (Si-1J, O-23IN) & $P B Y 1(\mathrm{Ec}-3 \mathrm{~J})$ & $P B Y 2(\mathrm{~T}-4 \mathrm{~B})$ \\
\hline Rmo2.a & $\mathrm{H} 4, \mathrm{NZ}$ & + & - & - & - & - \\
\hline Rmo2.b & $\mathrm{Npl}$ & + & + & - & - & - \\
\hline Rmo2.d & R81 & ND & ND & ND & + & + \\
\hline
\end{tabular}

a Avirulence genes are in italics and carriers of the avirulence gene are in parentheses; $+=$ yes, $-=$ no, and ND $=$ not determined 
trolling the avirulence of $\mathrm{Si}-1 \mathrm{~J}$ on wheat cultivars (16). To identify Rwtl (a hypothetical resistance gene corresponding to PWT1), Chuma et al. (3) screened common wheat cultivars for a noncarrier of Rwtl using a $\mathrm{BC}_{1} \mathrm{~F}_{1}$ population in which PWT1 segregated. Unfortunately, all common wheat cultivars tested recognized $P W T 1$ and, therefore, were presumed to be Rwt 1 carriers. In the present study, we found a barley cultivar (Ngt) that did not recognize $P W T 1$, which made it possible to identify Rmo2.a corresponding to $P W T 1$ in a gene-for-gene manner. Rmo 2 might possibly be a barley ortholog of $R w t 1$.

Interestingly, Rmo2.b, Rmo2.c, and Rmo2.d corresponded to more than one avirulence gene. If each of these alleles is actually composed of a single gene, it is a deviation from the gene-forgene theory (6). Interactions between one resistance gene and more than one avirulence gene have been reported in bacterial $(2,5,7,14)$ and oomycete $(8)$ systems. Alternatively, each of the alleles at the Rmo2 locus may be composed of more than one gene at the molecular level. To clone the Rmo2 locus, a fine mapping is under way.

The identification of Rmo2 and Rmo3 is primarily attributable to the finding of the universal suscept, Ngt. However, it raises the question of why Ngt is so susceptible to blast isolates. When Ngt is grown in a field, its heading is much earlier than that of the other barley cultivars. Due to this trait, Ngt may be harvested before Magnaporthe isolates start their infection cycles in natural fields. It should be noted that, when incubated at lower temperature $\left(<20^{\circ} \mathrm{C}\right)$ after inoculation with $\mathrm{Si}-1 \mathrm{~J}$ or O-23IN, Ngt sometimes produces pale brown flecks. Ngt might have had the Rmo2 gene but have gradually lost its function through accumulation of mutations because its function is unnecessary due to the ecological escape.

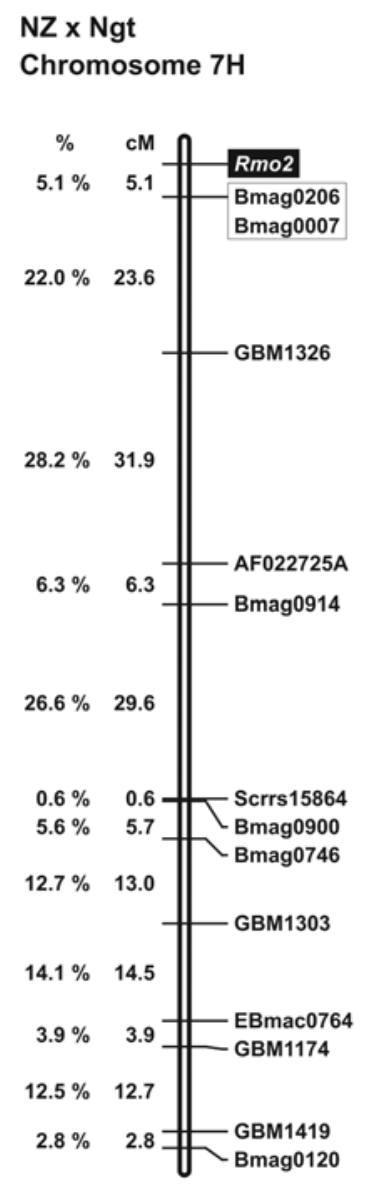

Fig. 3. Linkage map of the $7 \mathrm{H}$ chromosome constructed using an $\mathrm{F}_{2}$ population derived from the cross 'Nakaizumi-zairai' (NZ) $\times$ 'Nigrate' $(N g t)$. Genotypes of the $\mathrm{F}_{2}$ plants were determined using $\mathrm{F}_{3}$ seedlings.

\section{ACKNOWLEDGMENTS}

We thank U. Hiura, an emeritus professor at Okayama University, and $\mathrm{K}$. Tsunewaki, an emeritus professor at Kyoto University, for providing the barley and wheat cultivars; K. Sato, Okayama University, and K. Yoshida, Iwate Biotechnology Research Center, for critical reading the manuscript; R. Mori, Kobe University, for technical assistance; S. Mayama, an emeritus professor at Kobe University, for constant support, encouragement, and suggestions; and H. Kato, a former professor at Kobe University, for providing the isolates, detailed information on them, and valuable suggestions.

\section{LITERATURE CITED}

1. Appels, R., and Moran, L. B. 1984. Molecular analysis of alien chromatin introduced into wheat. Stadler Genet. Symp. 16:529-557.

2. Bisgrove, S. R., Simonich, M. T., Smith, N. M., Sattler, A., and Innes, R. W. 1994. A disease resistance gene in Arabidopsis with specificity for two different pathogen avirulence genes. Plant Cell 6:927-933.

3. Chuma, I., Zhan, S.-W., Asano, S., Nga, N. T. T., Vy, T. T. P., Shirai, M., Ibaragi, K., and Tosa, Y. 2010. PWT1, an avirulence gene of Magnaporthe oryzae tightly linked to the rDNA locus, is recognized by two staple crops, common wheat and barley. Phytopathology 100:436-443.

4. Couch, B. C., and Kohn, L. M. 2002. A multilocus gene genealogy concordant with host preference indicates segregation of a new species, Magnaporthe oryzae, from M. grisea. Mycologia 94:683-693.

5. De Feyter, R., Yang, Y., and Gabriel, D. W. 1993. Gene-for-genes interactions between cotton $R$ genes and Xanthomonas campestris pv. malvacearum avr genes. Mol. Plant-Microbe Interact. 6:225-237.

6. Flor, H. H. 1956. The complementary genic systems in flax and flax rust. Adv. Genet. 8:29-54.

7. Grant, M. R., Godiard, L., Straube, E., Ashfield, T., Lewald, J., Sattler, A., Innes, R. W., and Dangl, J. L. 1995. Structure of the Arabidopsis $R P M 1$ gene enabling dual specificity disease resistance. Science 269:843846.

8. Hall, S. A., Allen, R. L., Baumber, R. E., Baxter, L. A., Fisher, K., Bittner-Eddy, P. D., Rose, L. E., Holub, E. B., and Beynon, J. L. 2009. Maintenance of genetic variation in plants and pathogens involves complex networks of gene-for-gene interactions. Mol. Plant Pathol. 10:449457.

9. Hamer, J. E., Farrall, L., Orbach, M. J., Valent, B., and Chumley, F. G. 1989. Host species-specific conservation of a family of repeated DNA sequences in the genome of a fungal plant pathogen. Proc. Natl. Acad. Sci. USA 86:9981-9985.

10. Hirata, K., Kusaba, M., Chuma, I., Osue, J., Nakayashiki, H., Mayama, S., and Tosa, Y. 2007. Speciation in Pyricularia inferred from multilocus phylogenetic analysis. Mycol. Res. 111:799-808.

11. Inukai, T., Vales, M. I., Hori, K, Sato, K., and Hayes, P. M. 2006. RMo1 confers blast resistance in barley and is located within the complex of resistance genes containing Mla, a powdery mildew resistance gene. Mol. Plant-Microbe Interact. 19:1034-1041.

12. Kachroo, P., Ahuja, M., Leong, S. A., and Chattoo, B. B. 1997. Organization and molecular analysis of repeated DNA sequences in the rice blast fungus Magnaporthe grisea. Curr. Genet. 31:361-369.

13. Kato, H., Yamamoto, M., Yamaguchi-Ozaki, T., Kadouchi, H., Iwamoto, Y., Nakayashiki, H., Tosa, Y., Mayama, S., and Mori, N. 2000. Pathogenicity, mating ability and DNA restriction fragment length polymorphisms of Pyricularia populations isolated from Gramineae, Bambusoideae and Zingiberaceae plants. J. Gen. Plant Pathol. 66:30-47.

14. Kim, Y. J., Lin, N.-C., and Martin, G. B. 2002. Two distinct Pseudomonas effector proteins interact with the Pto kinase and activate plant immunity. Cell 109:589-598.

15. Koebner, R. M. D., Appels, R., and Shepherd, K. W. 1986. Rye heterochromatin. II. Characterization of a derivative from chromosome 1DS/1RL with a reduced amount of the major repeating sequence. Can. J. Genet. Cytol. 28:658-664.

16. Murakami, J., Tosa, Y., Kataoka, T., Tomita, R., Kawasaki, J., Chuma, I., Sesumi, Y., Kusaba, M., Nakayashiki, H., and Mayama, S. 2000. Analysis of host species specificity of Magnaporthe grisea toward wheat using a genetic cross between isolates from wheat and foxtail millet. Phytopathology 90:1060-1067.

17. Takabayashi, N., Tosa, Y., Oh, H. S., and Mayama, S. 2002. A gene-forgene relationship underlying the species-specific parasitism of Avenal Triticum isolates of Magnaporthe grisea on wheat cultivars. Phytopathology 92:1182-1188.

18. Taylor, J. W., Jacobson, D. J., Kroken, S., Kasuga, T., Geiser, D. M., Hibbett, D. S., and Fisher, M. C. 2000. Phylogenetic species recognition and species concepts in fungi. Fungal Genet. Biol. 31:21-32.

19. Tosa, Y., Hirata, K., Tamba, H., Nakagawa, S., Chuma, I., Isobe, C., Osue, 
J., Urashima, A.S., Don, L.D., Kusaba, M., Nakayashiki, H., Tanaka, A., Tani, T., Mori, N., and Mayama, S. 2004. Genetic constitution and pathogenicity of Lolium isolates of Magnaporthe oryzae in comparison with host species-specific pathotypes of the blast fungus. Phytopathology 94:454-462.

20. Tosa, Y., Tamba, H., Tanaka, K., and Mayama, S. 2006. Genetic analysis of host species specificity of Magnaporthe oryzae isolates from rice and wheat. Phytopathology 96:480-484.

21. Varshney, R. K., Marcel, T. C., Ramsay, L., Russell, J., Röder, M. S., Stein, N., Waugh, R., Langridge, P., Niks, R. E., and Graner, A. 2007. A high density barley microsatellite consensus map with 775 SSR loci. Theor. Appl. Genet. 114:1091-1103.

22. Yaegashi, H. 1988. Inheritance of blast resistance in two-rowed barley. Plant Dis. 72:608-610. 